\title{
美捷登2019-2020年度大会 璀璨华彩你我共享，遇见美好乘风破浪！
}

王雯雯

武汉美捷登生物科技有限公司

2020 年 8 月 7 日，立秋时节，在这收获季节的 伊始, 美捷登 2019-2020 年度总结暨表彰大会隆重 召开。美捷登的公司领导和员工们欢聚一堂, 用盛大 的典礼回馈2019-2020年的辛勤努力, 共享璀骤华彩, 遇见美好未来!

年会在美捷登主席夏华向教授的致辞中拉开序 幕。2020 年上半年是不平凡的开端, 新冠疫情汹涌 来袭, 在此期间, 美捷登的员工们能积极响应公司号 召, 克服困难, 努力工作, 保证公司各项业务正常开 展并且取得了优秀的业绩成果。对此, 夏教授及公司 高层向美捷登全体员工表示了衷心的感谢, 充分肯定 了员工们这一年来的各项工作成果, 同时希望全体员 工在新的一年里, 继续努力, 开拓创新, 积极为公司
的发展建言献策，共同铸就美捷登闪耀的未来!

美捷登主席夏教授致辞后，公司各部门开始了一 年一度的工作总结汇报, 各部门将 2019-2020 年的 各项工作进行回顾总结, 与在座的其他部门同事分享 工作成果与经验, 探讨工作中的不足, 寻求改进完善 之法。各部门在此次的工作汇报中, 加深了对其他部 门工作的了解, 也增进了部门间的默契度。

人才是美捷登生存和发展之本, 公司的发展离 不开每一位员工的努力和奋斗, 其中涌现出不少闪 闪发光的佼佼者们, 年会的颁奖环节因为他们异常 绚丽夺目。本次颁奖环节共颁发了五大奖项: 优秀 员工奖、优秀新员工奖、员工工龄奖、《Rising Sun》 原创文章奖、员工启新奖。公司领导为获奖员工们

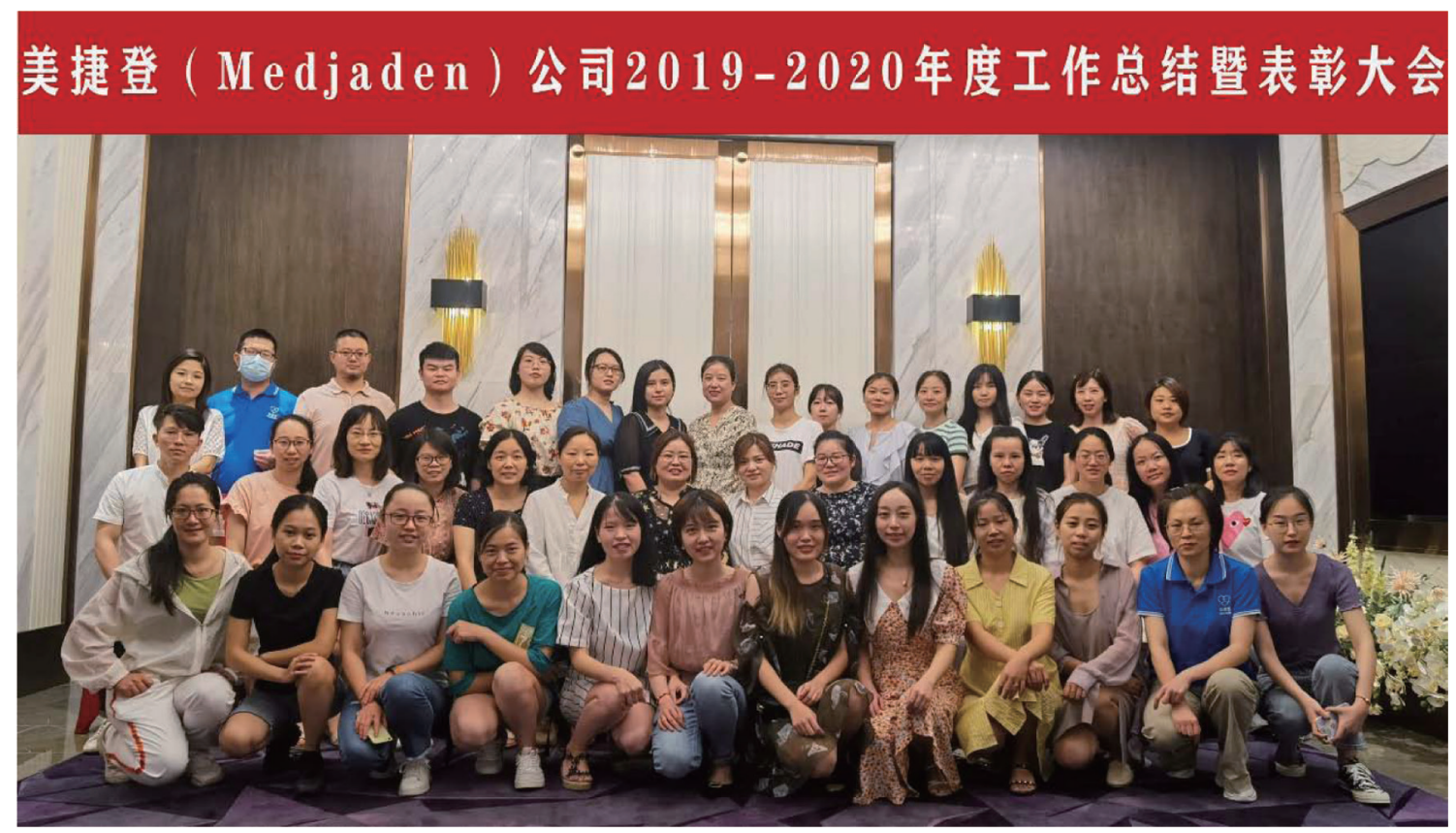




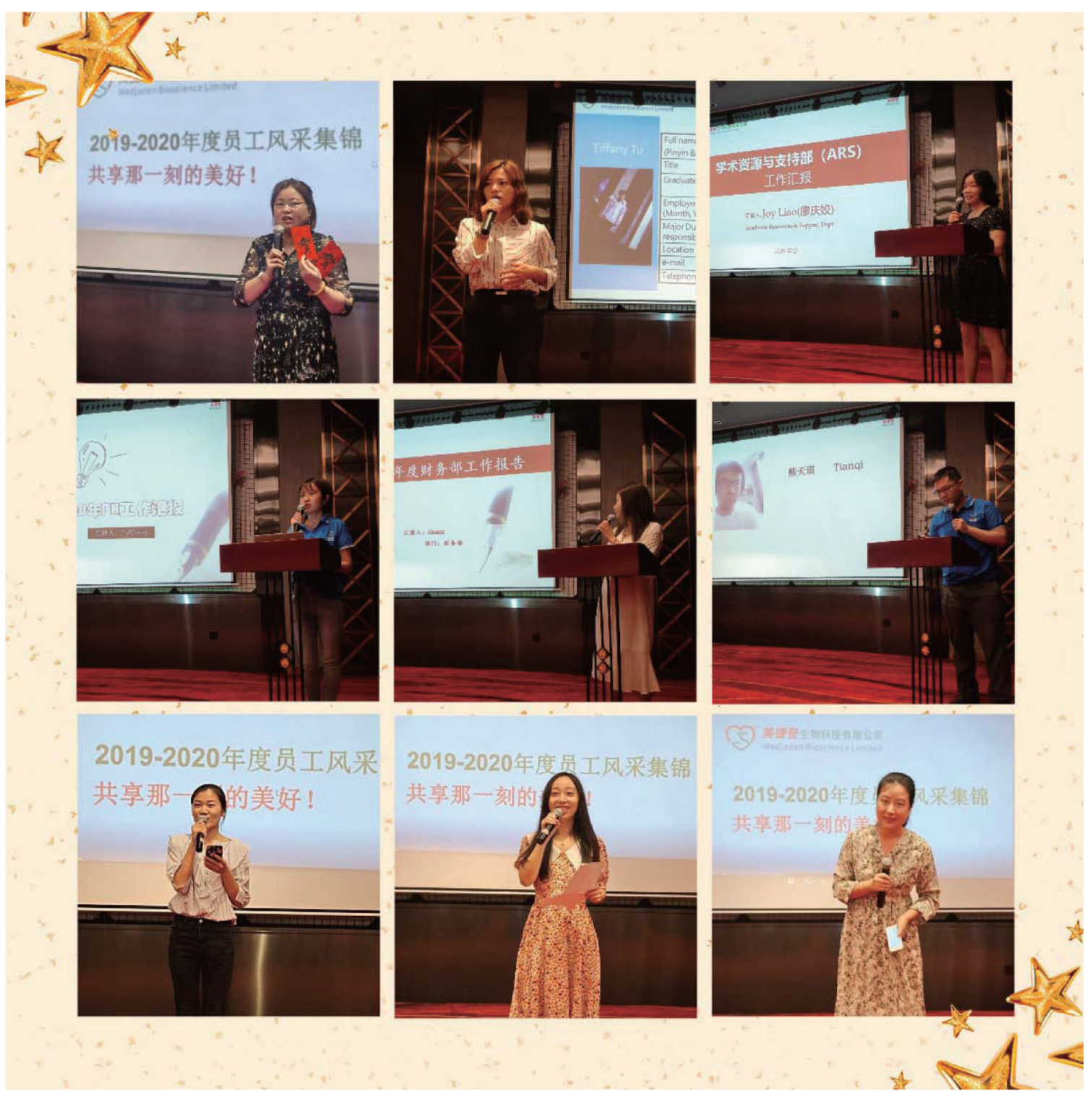

颁发了荣誉证书和奖金, 现场掌声、欢呼声此起彼伏, 会场气氛达到了最燃点。台上获奖的员工们硕果累 累, 脸上洋溢着收获的喜悦, 台下的员工们用热烈的 掌声向获奖者表示祝贺。颁奖环节过后, 优秀员工 代表们相继上台发言, 从他们的发言中, 我们看到了 榜样的力量, 激励着我们每一位员工积极进取、精 益求精，不断超越自我，创造不平凡！

年会的尾声，美捷登总经理何华女士进行总结 致辞, 她表示: 虽然 2020 年有许多的危机和挑战, 但是我们美捷登全体员工团结一心, 精诚合作, 共 同顺利渡过了疫情最艰难的那段日子。越是困难的 时候, 越能体现团队的力量, 我们美捷登就是一支 团结向上, 合作无间的团队。各位员工们齐心协力, 就一定可以化危机和挑战为动力, 在危机中寻找机
遇，让美捷登能持续不断地向前发展。

年度会议过后, 开启了木兰草原的旅程, 同事 们驱车来到了木兰故里, 感受广衰的草原风光, 亲 近久违的大自然。景区里还有新鲜刺激的彩虹滑道、 射箭、滑索飞渡、滑草等体验式游玩项目, 大家 一一游玩, 大呼过瘾, 意犹未尽。到了晚上, 同事 们围坐在烧烤炉边, 享用着美味的烧烤, 共同举杯 庆祝今年的年会圆满举行。夜深沉, 人沉醉, 在绚 烂烟花的祄托下，大家脸上的笑容更加明亮灿烂。

年会在大家的欢声笑语中落下帷幕, 相信团聚 时的欢乐会伴随着每一位员工, 让大家可以充满能 量、积极乐观地开启新一年多彩绚丽的征程。新的 一年, 我们美捷登人站在崭新的起点, 共同描绘美 捷登的美好蓝图, 谱写璀嗓华彩新篇章! 


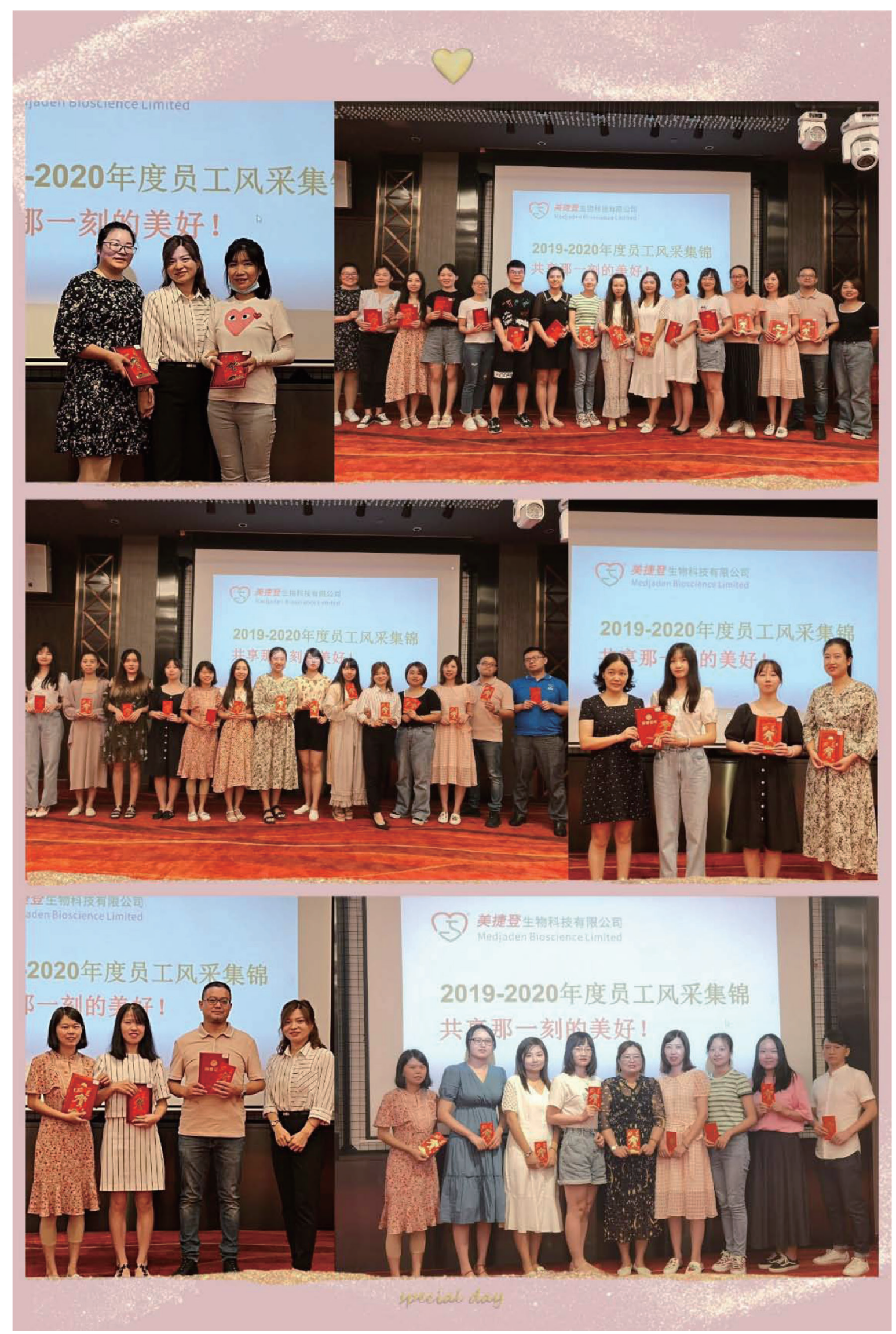



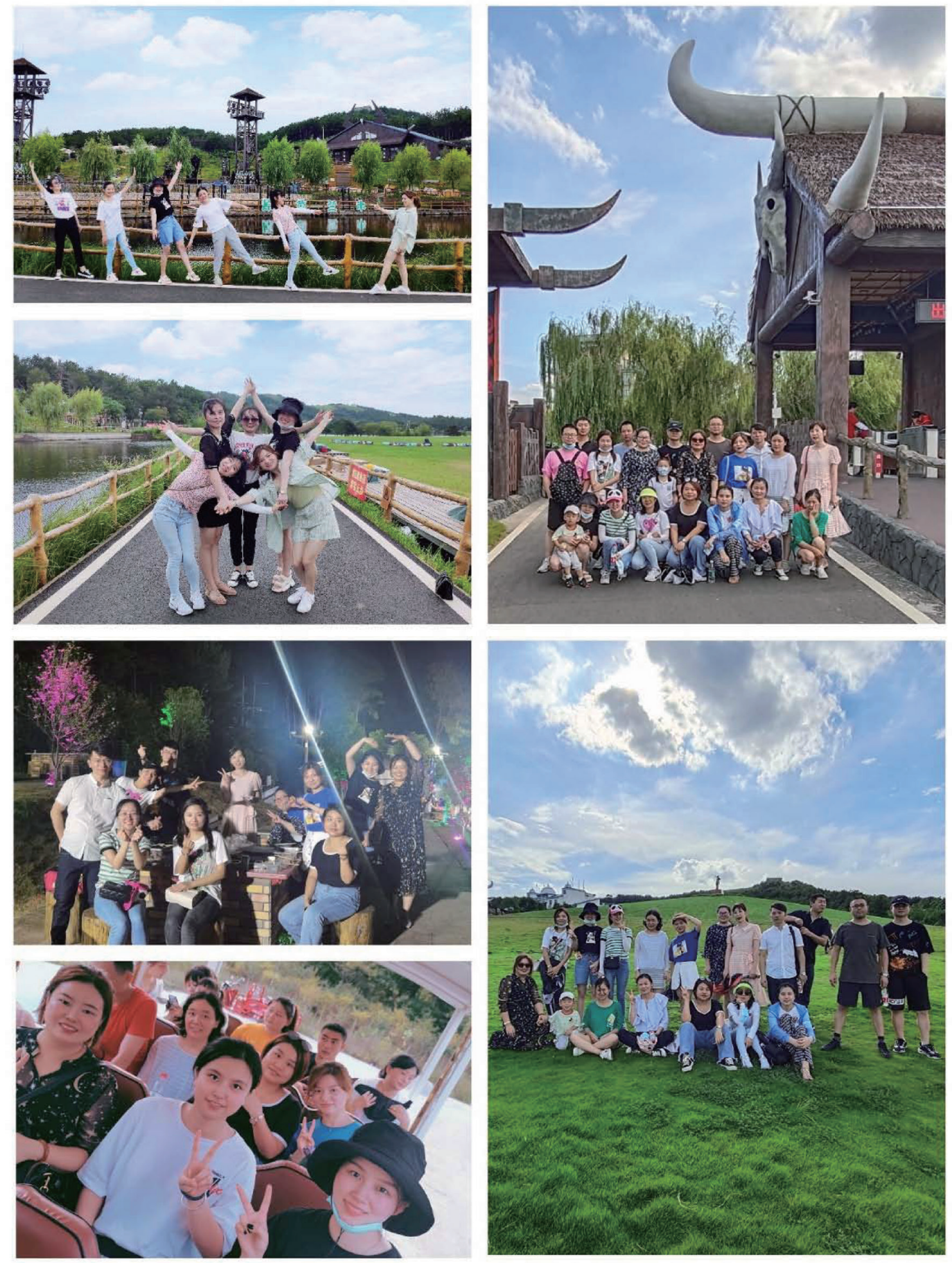